\title{
Two different presentations of de novo variants of CSNK2B: two case reports
}

\author{
Matheus V. M. B Wilke ${ }^{1,2}$, Bibiana M. Oliveira ${ }^{1,3,4}$, Alessandra Pereira5 ${ }^{5}$ Maria Juliana R. Doriqui', \\ Fernando Kok ${ }^{4}$ and Carolina F. M. Souza ${ }^{*}$
}

\begin{abstract}
Background: Poirier-Bienvenu neurodevelopmental syndrome is a neurologic disorder caused by mutations in the CSNK2B gene. It is mostly characterized by early-onset seizures, hypotonia, and mild dysmorphic features. Craniodigital syndrome is a recently described disorder also related to CSNK2B, with a single report in the literature.

Objective: To report two unrelated cases of children harboring CSNK2B variants (NM_001320.6) who presented with distinct diseases.

Case report: Case 1 is a 7-month-old, Caucasian, female patient with chief complaints of severe hypotonia and drugrefractory myoclonic epilepsy, with a likely pathogenic de novo variant c.494A $>\mathrm{G}$ (p.His165Arg). Case 2 is a 5 -yearold male, Latino patient with craniodigital intellectual disability syndrome subjacent to a de novo, likely pathogenic variant c.94G >T (p.Asp32Tyr). His dysmorphic features included facial dysmorphisms, supernumerary nipples, and left-hand postaxial polydactyly.

Conclusion: This report suggest that the CSNK2B gene may be involved in the physiopathology of neurodevelopmental disorders and variable dysmorphic features.
\end{abstract}

Keywords: Epilepsy, Hypotonia, Dysmorphic features, Case report

\section{Introduction}

Poirier-Bienvenu neurodevelopmental syndrome (POBINDS; OMIM \#618732) is a recently described disorder characterized by hypotonia, seizures, and developmental delay [1]. POBINDS is caused by mutations in the CSNK2B gene (located at 6p21.33), which encodes the beta subunit $(\mathrm{CK} 2 \beta)$ of the casein kinase 2 enzyme (CK2). It has been reported that the CSNK2B gene is neither susceptible to missense mutations $(Z=3.83)$ nor loss of function (pLi 0.92; observed/expected $=0.08$; $95 \%$ confidence interval 0.03-0.38). In fact, all cases reported have been subjacent to de novo mutations and caused variants that lead to loss of function [2].

*Correspondence: cfsouza@hcpa.edu.br

${ }^{1}$ Medical Genetics Service, Hospital de Clínicas de Porto Alegre, Rua Ramiro Barcelos, 2350 - 30 andar, Porto Alegre, RS 90035-007, Brazil

Full list of author information is available at the end of the article
Dysmorphic features other than those originally reported have recently been associated with craniodigital syndrome (CDS), a condition that can be distinguished from POBINDS [3]. However, these dysmorphic features are not fully characterized [4].

Th work aims to detail the clinical manifestations of patients with two $C S N K 2 B$ variants presenting with distinct phenotypes, one with the phenotype closer to POBINDS and another with the phenotype closer to CDS. To the best of our knowledge, only two cases have described patients with similar dysmorphic features. We also discuss possible pathogenic mechanisms based on a literature review, emphasizing the necessity to better elucidate the clinical phenotype spectrum related to the CSNK2B gene. original author(s) and the source, provide a link to the Creative Commons licence, and indicate if changes were made. The images or other third party material in this article are included in the article's Creative Commons licence, unless indicated otherwise in a credit line to the material. If material is not included in the article's Creative Commons licence and your intended use is not permitted by statutory regulation or exceeds the permitted use, you will need to obtain permission directly from the copyright holder. To view a copy of this licence, visit http://creativecommons.org/licenses/by/4.0/. The Creative Commons Public Domain Dedication waiver (http://creativeco mmons.org/publicdomain/zero/1.0/) applies to the data made available in this article, unless otherwise stated in a credit line to the data. 

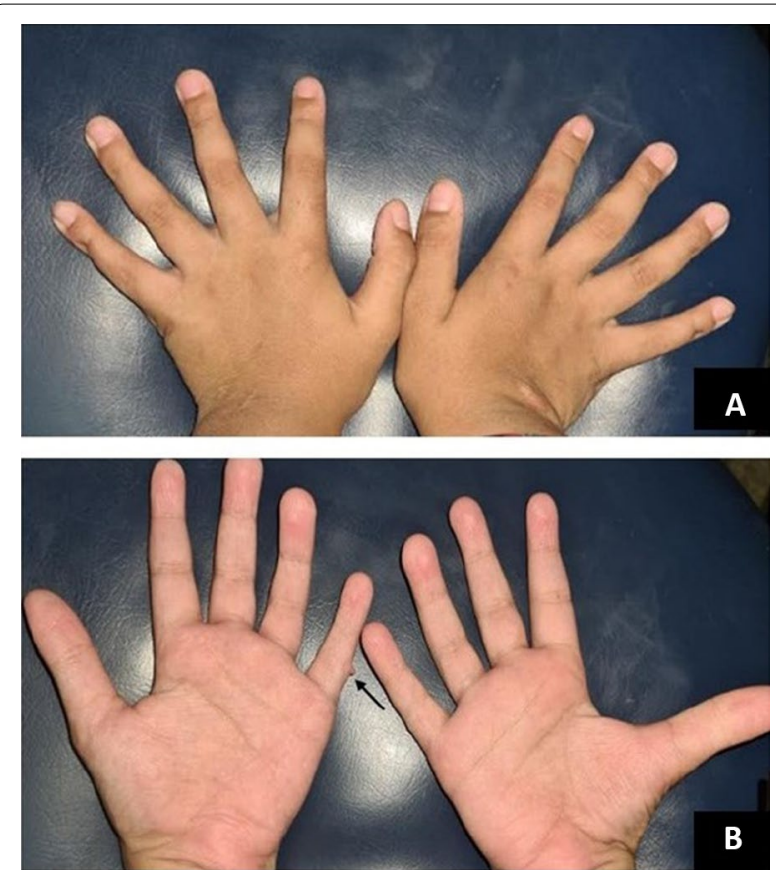

Fig. 1 Hands of patient \#2: The patient from the second case report showed fifth short fingers,tapered distal phalanges of fingers, left hand postaxial polydactyly (surgically corrected, pointed by the arrow) and nail hypoplasia in the $(\mathbf{A})$ and $(\mathbf{B})$ panels

\section{Case report}

\section{Case \# 1: Hypotonia and neonatal myoclonic spasm}

A 7-month-old, female Caucasian patient presented with neurodevelopmental delay followed by epilepsy with unaltered electroencephalogram (EEG). The patient is the second child of a nonconsanguineous couple, having an 11-year-old healthy brother. No other family member had a medical history of neurological or genetic disorders. Although the pregnancy was uneventful, the patient was delivered by cesarean due to placental detachment with a gestational age of $39+1$ weeks. The patient was a full-term infant with birth weight of $3.4 \mathrm{~kg}$ and APGAR score of 6 and 8 in the first and fifth minutes, respectively. Due to myoclonic movements, hypotonia, and cyanosis, the patient was admitted to the neonatal intensive care unit.

At the age of 23 days, the patient was referred to a Reference Center in Rare Genetic Diseases at the Porto Alegre University Hospital. The epileptiform crisis evolved to recurring focal motor seizures in the upper limbs with simultaneous apnea. The physical evaluation revealed marked global hypotonia and dysmorphic features such as midfacial hypoplasia, bilateral strabismus, tongue protrusion, and dysplastic ears (overfolded helix) as shown in Fig. 1.
The patient underwent a metabolic genetic investigation, which included normal urinary organic acids and quantitative plasma amino acids. Empiric treatment with biotin and pyridoxine failed to result in any improvement of her clinical picture. Neuroimaging study (magnetic resonance imaging, MRI) did not reveal any abnormality and the EEG was unaltered even when it was performed during the myoclonic movements. Due to global hypotonia, further investigation ruled out Prader Willi Syndrome, Pompe disease, and congenital disorders of glycosylation. Karyotype was also unchanged, and the chromosomal microarray revealed a duplication of the 1 p31.3 (61236531_61661276), which was considered a variant of uncertain significance.

Laryngeal fiberscopic evaluation revealed an obstructive laryngomalacia. The patient underwent a supraglottoplasty at the age of 1 month. Despite the procedure, the spasms persisted. The patient was then discharged from the hospital for further follow-up in the outpatient clinic with the diagnostic hypothesis of sleep myoclonus.

At the age of 7 months, physical examination revealed severe global development delay (inability to lift the head) due to truncal hypotonia. Her epilepsy had worsened (intensity and duration of the episodes) being considered a pharmacoresistent myoclonic epilepsy triggered by both auditory and visual stimuli.

The exome sequencing revealed a de novo likely pathogenic CSNK2B variant (NM_001320.6). The variant c. $494 \mathrm{~A}>\mathrm{G}$ (p.His165Arg) is present in exon 6 out of 7 exons, in a highly conserved amino acid and it is not observed in The Genome Aggregation Database (gno$\mathrm{mAD})$. In silico tools predict the variant to be deleterious (SIFT: Damaging 0; Revel: Deleterious low; CADD Score: 26.1). The variant is found in the Human Gene Mutation Database (HGMD) as a disease-causing mutation (DM). No other pathogenic variation was found in other epilepsy candidate genes.

\section{Case \#2: Hypotonia and dysmorphisms}

A 5-year-old, male Latin patient was referred for genetic evaluation at the age of 13 months, with the chief complaints of dysmorphisms, hypotonia, and developmental delay.

The patient was born from a nonconsanguineous young couple. He was also delivered by cesarean section due to placental detachment, with a gestational age of 41 weeks. He was a full-term infant with birth weight of $3.4 \mathrm{~kg}$ and APGAR score of 9 in the first and fifth minutes.

The patient's motor development was considered delayed: the patient sustained his head at the age of 6 months, sat unassisted at the age of 8 months, and 
walked independently at 2.4 years. At 9 months of age, the patient presented with acute episodes of muscle tone loss associated with abnormal eye movements. The EEG performed at 1 year showed disorganized basal activity, which was considered to be related to brain immaturity. The sleep-related graph elements did not show any epileptiform paroxysmal waves.

Physical examination revealed axial hypotonia, microbrachycephaly, low nasal bridge, anteverted nares, malar hypoplasia, high and narrow palate, duplicated upper right incisor, prominent and dysplastic ears, and supernumerary nipples. Examination of the extremities showed short fifth fingers, tapered distal phalanges of fingers, left hand postaxial polydactyly (surgically corrected), and nail hypoplasia, as shown in Fig. 1.

Genetic evaluation included karyotype and chromosomal microarrays, which were unaltered. Exome sequencing identified a de novo missense pathogenic CSNK2B variant (NM_001320.6) in heterozygosis. The variant c.94G $>\mathrm{T}$ is present in exon 3 out of 7 exons, with a highly conserved amino acid sequence, which are not described in the gnomAD. In silico tools predicted that the variant is likely deleterious (SIFT: Damaging 0; Revel: Deleterious high; CADD Score: 32). In HGMD, the variant position was already reported, leading to a different amino acid substitution (c.94G >A; p.Asp32Asn) and subjacent to the same phenotype. Sanger sequencing confirmed the presence of the variant in the patient but not in the parents.

\section{Discussion}

After the initial report of POBINDS [1], two subsequent papers documented the medical history of three unrelated patients with marked impaired global development and complex partial seizures before 2 months of age $[5,6]$. The refractory seizures observed in these patients included focal evolving to generalized tonicclonic episodes, and epileptic encephalopathy. Epilepsy in POBINDS is also characterized by unaltered EEG and MRI. Being drug resistant, tonic-clonic seizures are the most frequent presentation $[2,7,8]$. The absence of a specific imaging pattern corroborated in both of our cases to a delayed diagnosis, as exemplified in Case \#1 where sleep myoclonus was one of the differential diagnosis owing to the unaltered EEG.

Few in vivo studies have demonstrated the interaction of CK2 and voltage channels that could explain the epilepsy seen in these patients. Potassium channels are the most diverse group of the ion channel family. These channels are not only involved in shaping the action potential, but also in neuronal excitability and plasticity. One study using transfected Chinese hamster ovary cells expressing Kv3.1 (a potassium channel with a very high threshold) demonstrated the importance of its phosphorylation by CK2. When CK2 was inhibited, there was a decrease in the phosphorylation of the Kv3.1 channels, leading to the decline in its electric potentials $[9,10]$. Although speculative, it might be related to the etiology of seizures found in these patients.

The most striking clinical feature of Case \#2 was the dysmorphic features that were recently associated with CDS, which could be distinguished from POBINDS [3]. A recently published paper reported the case of a young male Japanese patient with a deletion of $6 \mathrm{p} 21.33$ (which encompasses the CSNK2B gene). The patient displayed very similar features to patient \#2, including large lowset ears, downslanted palpebral fissures, flared eyebrows, wide-base nose, and flat philtrum with thin upper lip [11] (for further details, see [8] and Table 1). Collectively, these cases corroborate the loss of function as plausible mechanisms described for both POBINDS and CDS.

CK2 is a heterotrimeric enzyme consisting of two catalytic CK $2 \alpha$ or $\mathrm{CK} 2 \alpha^{\prime}$ subunits and two regulatory $\beta$ subunits. It also contains several distinct domains. The three main domains are Asp/Glu-enriched (acidic), zinc-binding (where the dimerization of $\beta$ subunit occurs), and $\alpha$-subunit-interaction domains $[12,13]$. Even though it is considered a regulatory subunit, CK2 $\beta$ is highly conserved. Previous studies have demonstrated that if this regulatory subunit is excessively synthesized, there is a trend to the formation of of CK2 $\beta$ dimers, which are, in turn, a prerequisite for the formation and correct function of the whole enzyme $[12,14]$.

It is believed that the zinc-binding domain might be a hotspot for pathogenic variants and that the $\alpha$-subunitinteraction domain might be the one related to refractory myoclonic epilepsy $[2,15]$. The closest zinc binding site in the variant-related protein from patient\#1 is a cysteine in position 137. However, p.His165Arg, according to crystal structure, is in close interaction with the complementary beta subunit, as seen in Fig. 2. The dimers of CK2 $\beta$ are located at the core of the tetrameric CK2 complexes and we hypothesize that symptoms observed in patient \#1 might be due to alterations in this beta-beta interaction, subsequently leading to a disruption in the CK2 $\beta$ dimerization.

Two de novo missense mutations (p.Asp32Asn and p.Asp32His) in the same CSNK2B codon, which is mutated in patient \#2, have recently been associated with CDS [3, 7]. Due to the modification of the CK2 structure, the closest CK2 catalytic subunit would be position 32, which could exert a more severe dysmorphic phenotype. One study using whole transcriptome and whole phosphoproteome profiling demonstrated that variants in this protein amino acid position caused an up-regulation of CSNK2B gene expression at transcript and protein levels, 
Table 1 Comparison of the clinical phenotype of patients described in this paper with those in [11]

\begin{tabular}{|c|c|c|c|}
\hline Clinical Features & Case 1 & Case 2 & {$[11]$} \\
\hline Genotype & c.494A>G (p.His165Arg)/- & c.94G>T(p.Asp32Tyr)/- & 6p.21.33 deletion/- \\
\hline Perinatal history & Placental detachment & Placental detachment & Uneventful \\
\hline Hypotonia & Yes & Yes & Yes \\
\hline ID/DD & Yes & Yes & Yes \\
\hline Gross motor development delay & Yes & Yes & Yes \\
\hline $\begin{array}{l}\text { Development of speech and } \\
\text { language }\end{array}$ & Yes & No & Yes \\
\hline Facial dysmorphisms & $\begin{array}{l}\text { Midfacial hypoplasia, bilateral } \\
\text { strabismus, lingual protrusion, and } \\
\text { over-folded helices }\end{array}$ & $\begin{array}{l}\text { Microbrachycephaly, low nasal } \\
\text { root, anteverted nostrils, malar } \\
\text { hypoplasia, high and narrow palate, } \\
\text { duplicated upper right incisor, } \\
\text { prominent and dysplastic ears }\end{array}$ & $\begin{array}{l}\text { Relative macrocephaly. Large low-set } \\
\text { ears, downslanting palpebral fissures, } \\
\text { flared eyebrows, wide-base nose, and } \\
\text { flat philtrum with thin upper lip }\end{array}$ \\
\hline Other dysmorphisms & No & $\begin{array}{l}\text { Supernumerary nipples, short fifth } \\
\text { fingers, distal tapering of fingers, } \\
\text { left hand postaxial polydactyly, and } \\
\text { nail hypoplasia }\end{array}$ & ND \\
\hline Age at seizure onset & Newborn & 9 months & ND \\
\hline Seizure types & Myoclonic spasms & Atonic Seizures & ND \\
\hline Familiar recurrence & No & No & No \\
\hline EEG & Normal & Disorganized base activity & ND \\
\hline Brain image & Normal & Normal & Incomplete hippocampal folding \\
\hline Other & Obstructive laryngomalacia & No & Asthma attacks and food allergies \\
\hline
\end{tabular}

resulting in impaired cross talk between $\alpha$ and $\beta$ subunits of CK2 [3]. Both hypotheses, however, must be further demonstrated by functional studies. A definite association between phenotype and genotype in CSNK2B generelated epilepsy has still not been described [2].

A hypothesis for the POBINDS-related "brain-centered symptoms" could be raised after preclinical research on the CK2 function in animal cell models. The CK2 subunit appears to be constitutively active, being a target for dopamine D1 receptors signaling pathway $[1,16]$. The resulting alterations in the dopaminergic system (as per increased D1 receptor signaling and/or dopamine production) has also been found in patients with juvenile myoclonic epilepsy [8], possibly contributing to understanding of myoclonic epilepsy, as well as the excessive sweating observed in the patient in case \#1.

Additionally, a study using GN11 cells as a model of immature migrating neurons, demonstrated that CK2 $\beta$ was involved in cell migration and microfilament/ microtubule organization in neurons, thus playing a role in neurodevelopmental steps such as neural differentiation, neuritogenesis, and synaptic plasticity $[15$, 17]. In line with these findings, studies using $\beta$ subunit CK2 knockout cell lines $(K O \beta)$ pointed out that the $\beta$ subunit may serve as an anchorage point for other kinases, being involved in the myogenic commitment of $\mathrm{C} 2 \mathrm{C} 12$ (myogenic cell lines in murines) by regulating MyoD expression independently from the catalytic subunits $[15,17]$. In a C2C12 model, CK2 $\beta$ contributes to a variety of cell cycle processes such as proliferation and cellular transport in vitro. Collectively, these findings might contribute to the elucidation of the hypotonia presented by both patients. CK2 has also been implicated in organogenesis, playing a role in heart embryogenesis and limb bud differentiation via the Wnt signaling pathway. Further studies are warranted to determine the association of this role to the limb dysmorphisms found in the patient from the second case [4].

\section{Conclusion}

To date, 16 patients have been reported in the literature with POBINDS and 2 patients have been reported with craniodigital intellectual disability syndrome related to mutations in the CSNK2B gene. The present cases may assist in the diagnosis of POBINS when patients present with refractory epilepsy, hypotonia, and dysmorphic features. Further investigation is warranted to better understand the interaction of CK2 and the neuronal and neuromuscular systems. We suggest that screening of $C S N K 2 B$ could be included in the most common gene panels for epilepsy. 


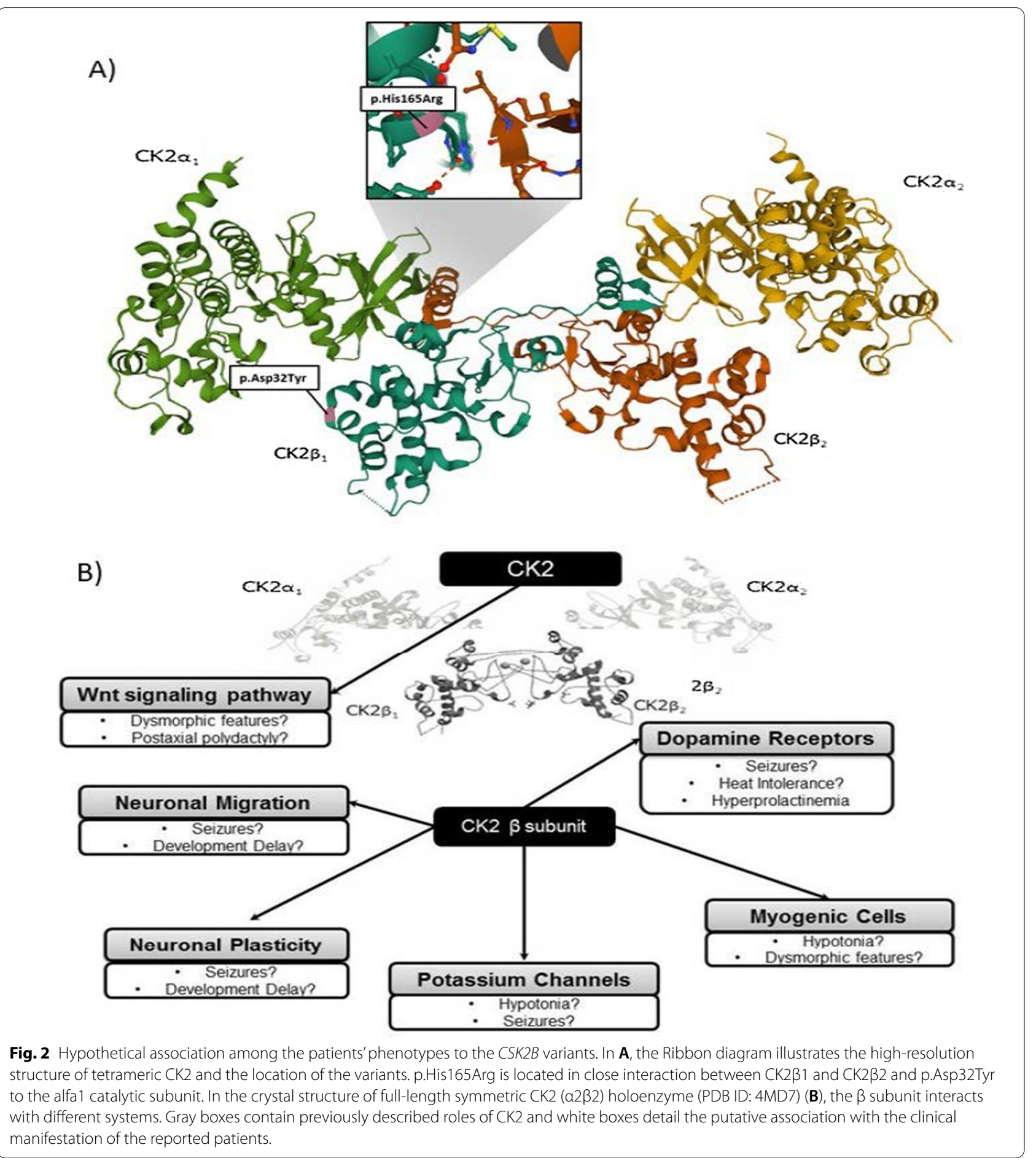

Abbreviations

ACMG: American College of Medical Genetics; CDS: Craniodigital syndrome; CMA: Chromosomal microarray; CK2: Casein kinase 2 enzyme; CK2 $\beta$ : Casein kinase 2 enzyme beta subunit.; EEG: Electroencephalogram; gnomAD: The Genome Aggregation Database; HGMD: Human Gene Mutation Database; LOF: Loss of function; POBINDS: Poirier-Bienvenu neurodevelopmental syndrome.

\section{Acknowledgements}

Not applicable.

\section{Authors' contributions}

CFMS and MJRD collected the clinical data. CFMS and MVMBW conceptualized the manuscript and drafted its first version. BMO and FK performed the genetic analysis of the patients. CFMS, BMO, FK, MJRD, and AP participated in 
critical analysis and review of the manuscript. All authors read and approved the final manuscript. Camilla Patti Hissamura provided language editing.

\section{Funding}

This research did not receive any specific grant from funding agencies in the public, commercial, or not-for-profit sectors.

\section{Availability of data and materials}

Data was retrieved from patients medical files from Hospital de Clinicas de Porto Alegre (Porto Alegre - RS, Brazil), Hospital Moinhos de Vento (Porto Alegre - RS, Brazil), Laboratorio Mendelics (Sao Paulo- SP Brazil) with consent.

\section{Declarations}

\section{Ethics approval and consent to participate}

All procedures followed were in accordance with the ethical standards of the Ethical Committee from the Hospital de Clínicas de Porto Alegre - Porto Alegre; RS; Brazil and Laboratório Mendelics - Sao Paulo; SP - Brazil and with the Helsinki Declaration of 2013, as revised in 2000.

\section{Consent for publication}

Written informed consent was obtained from the patients' legal guardian for publication of this case report and any accompanying images. A copy of the written consent is available for review by the Editor-in-Chief of this journal.

\section{Competing interests}

All authors declare no conflict of interest.

\section{Author details}

${ }^{1}$ Medical Genetics Service, Hospital de Clínicas de Porto Alegre, Rua Ramiro Barcelos, 2350 - $3^{\circ}$ andar, Porto Alegre, RS 90035-007, Brazil. ${ }^{2}$ Post Graduate Program in Medical Sciences, Universidade Federal do Rio Grande do Sul, Porto Alegre, RS, Brazil. ${ }^{3}$ Post Graduate Program in Genetics and Molecular Biology, Universidade Federal do Rio Grande do Sul, Porto Alegre, RS, Brazil. ${ }^{4}$ Mendelics Genomic Analysis, São Paulo, SP, Brazil. ${ }^{5}$ Pediatrics Service, Neuropediatrics, Hospital Moinhos de Vento, Porto Alegre, RS, Brazil. ${ }^{6}$ Hospital Infantil Dr. Juvêncio Mattos, São Luís, MA, Brazil.

Received: 21 September 2021 Accepted: 8 November 2021

Published online: 05 January 2022

\section{References}

1. Poirier K, Hubert L, Viot G, et al. CSNK2B splice site mutations in patients cause intellectual disability with or without myoclonic epilepsy. Hum Mutat. 2017;38:932-41. https://doi.org/10.1002/humu.23270.

2. Li J, Gao K, Cai S, et al. Germline de novo variants in CSNK2B in Chinese patients with epilepsy. Sci Rep. 2019;9:17909. https://doi.org/10.1038/ s41598-019-53484-9.

3. Asif M, Kaygusuz E, Shinawi M, et al. De novo pathogenic variants in CSNK2B cause a new intellectual disability-craniodigital syndrome distinguished from Poirier-Bienvenu neurodevelopmental syndrome. Eur J Hum Genet. 2020;28:129-31.

4. Lou DY, Dominguez I, Toselli P, et al. The alpha catalytic subunit of protein kinase CK2 is required for mouse embryonic development. Mol Cell Biol. 2008:28:131-9. https://doi.org/10.1128/MCB.01119-07.

5. Nakashima M, Tohyama J, Nakagawa E, et al. Identification of de novo CSNK2A1 and CSNK2B variants in cases of global developmental delay with seizures. J Hum Genet. 2019;64:313-22. https://doi.org/10.1038/ s10038-018-0559-z.

6. Sakaguchi Y, Uehara T, Suzuki H, et al. Truncating mutation in CSNK2B and myoclonic epilepsy. Hum Mutat. 2017;38:1611-2. https://doi.org/10.1002/ humu.23307.

7. Ernst ME, Baugh EH, Thomas A, et al. CSNK2B: a broad spectrum of neurodevelopmental disability and epilepsy severity. Epilepsia. 2021;62:e103-9. https://doi.org/10.1111/epi.16931.

8. Selvam $\mathrm{P}$, Jain A, Cheema A, et al. Poirier-Bienvenu neurodevelopmental syndrome: a report of a patient with a pathogenic variant in CSNK2B with abnormal linear growth. Am J Med Genet A. 2021;185:539-43. https://doi. org/10.1002/ajmg.a.61960.

9. Macica CM, Kaczmarek LK. Casein kinase 2 determines the voltage dependence of the Kv3.1 channel in auditory neurons and transfected cells. J Neurosci. 2001;21:1160-8. https://doi.org/10.1523/JNEUROSCI.21-04-01160. 2001.

10. Miller C. An overview of the potassium channel family. Genome Biol. 2000;1:reviews0004.1-reviews0004.5.

11. Ohashi I, Kuroda Y, Enomoto Y, et al. 6p21.33 Deletion encompassing CSNK2B is associated with relative macrocephaly, facial dysmorphism, and mild intellectual disability. Clin Dysmorphol. 2021;30:139-41. https://doi. org/10.1097/MCD.0000000000000372.

12. Niefind K, Guerra B, Ermakowa I, Issinger O-G. Crystal structure of human protein kinase CK2: insights into basic properties of the CK2 holoenzyme. EMBO J. 2001;20:5320-31. https://doi.org/10.1093/emboj/20.19.5320.

13. Raaf J, Brunstein E, Issinger O-G, Niefind K. The interaction of CK2a and $C K 2 \beta$, the subunits of protein kinase $C K 2$, requires $C K 2 \beta$ in a preformed conformation and is enthalpically driven. Protein Sci Publ Protein Soc. 2008;17:2180-6. https://doi.org/10.1110/ps.037770.108.

14. Graham KC, Litchfield DW. The regulatory $\beta$ subunit of protein kinase CK2 mediates formation of tetrameric CK2 complexes*. J Biol Chem. 2000;275:5003-10. https://doi.org/10.1074/jbc.275.7.5003.

15. Lettieri A, Borgo C, Zanieri L, et al. Protein kinase CK2 subunits differentially perturb the adhesion and migration of GN11 cells: a model of immature migrating neurons. Int J Mol Sci. 2019. https://doi.org/10.3390/ijms202359 51.

16. Poole A, Poore T, Bandhakavi S, et al. A global view of CK2 function and regulation. Mol Cell Biochem. 2005;274:163-70. https://doi.org/10.1007/ s11010-005-2945-z.

17. Der Vartanian A, Audfray A, Al Jaam B, et al. Protein O-fucosyltransferase 1 expression impacts myogenic $\mathrm{C} 2 \mathrm{C} 12$ cell commitment via the notch signaling pathway. Mol Cell Biol. 2015;35:391-405. https://doi.org/10.1128/MCB. 00890-14.

\section{Publisher's Note}

Springer Nature remains neutral with regard to jurisdictional claims in published maps and institutional affiliations.

Ready to submit your research? Choose BMC and benefit from

- fast, convenient online submission

- thorough peer review by experienced researchers in your field

- rapid publication on acceptance

- support for research data, including large and complex data types

- gold Open Access which fosters wider collaboration and increased citations

- maximum visibility for your research: over 100M website views per year

At BMC, research is always in progress.

Learn more biomedcentral.com/submissions 